\title{
INTRODUCTION: MUTUAL HELP IN AN ERA OF UNCERTAINTY
}

\section{Daivi Rodima-Taylor and Erik Bähre}

\begin{abstract}
African communities are witnessing a perplexing proliferation of diverse arrangements of mutual security that draw upon old and new solidarities and inventively merge market logic with reciprocal forms of distribution and sharing. The dynamics of such voluntary arrangements and their broader social impacts emerge as increasingly important topics of study. The changing nature of global economies poses challenging questions about the novel relationships between state and market, and the potential of human agency to find alternatives to address growing inequalities. This collection focuses on local institutions of mutual security as alternative-yet also interdependent-forms of distribution that have become particularly relevant in the current era of global financialization and the changing dynamics between private and public social spheres. Various voluntary associations and informal economic networks, financial mutuals and savings/credit groups are becoming central in regulating access to resources and defining patterns of association in African communities. The articles in this themed part-issue explore these social security networks and organizations, concentrating on their ambiguous potential to empower the marginal as well as to contribute to social strife and political conflict. Ethnographic cases from diverse parts of Africa illustrate the impacts of the environments of uncertainty on the emergence of novel forms of association. The contributions suggest that contemporary mutual help arrangements should be seen as being central to the emergence of new social spaces and power configurations in such settings, revealing a broader social dynamic of globalization.

African economies are increasingly affected by global financial instabilities and the changing role of money in social life. Global financial deregulation has led to a proliferation of innovative financial products and the increasing 'financialization' of world economies, with a focus on credit and private investment, highlighting the need to reconsider the relationships between the state and the market (Maurer 2005; Hart and Ortiz 2008). In the anthropological study of the distribution of resources, a fuller integration of the financial with the social and the political is called for. Alternative and informal modes of distribution that draw upon novel arrangements of solidarity have become particularly relevant in
\end{abstract}

\footnotetext{
DAIVI RODIMA-TAYLOR is Research Associate at the Center for Finance, Law \& Policy of Boston University, and Visiting Researcher at the African Studies Center. She is lead researcher of Boston University's interdisciplinary task force on migrant remittances and post-conflict development. She has also published on the topics of cooperation, fiduciary culture, environmental management and institutional innovation in Africa. Email: rodima@bu.edu ERIK BÄHRE is Assistant Professor at the Institute of Cultural Anthropology and Development Sociology at Leiden University. He was a researcher at the London School of Economics and a research fellow at the Netherlands Institute of Advanced Studies (NIAS). He is the author of Money and Violence: financial self-help groups in a South African township (Brill 2007). Email: ebaehre@fsw.leidenuniv.nl
} 
African communities over the past few decades of neoliberal deregulation reforms. An unprecedented growth in informal economic arrangements has occurred, encompassing diverse social and ethnic categories and facilitating the emergence of new public spaces and moralities (Lindell 2010; Bryceson 2010). The ongoing global expansion of the financial sector and the ideology of financial inclusion underline the importance of alternative sources of finance for people's livelihoods (cf. Hull and James 2012). The resulting plural economic forms that strive to balance the tension between self-interest and mutuality can be seen as a distinguishing feature of the contemporary human economy (Hart et al. 2010). Instead of assuming a trend towards an increasing abstraction of finance, it is important to investigate diverse local 'monetary repertoires and practices' (Maurer 2005: 17; Guyer 2004; see also Bähre 2007; Rodima-Taylor 2013).

Although mutual security associations play an increasingly important role in the emerging configurations of network governance in many African societies (see also Comaroff and Comaroff 2012; Meagher 2010), there is still scarce anthropological study of mutual help in its contemporary forms. The relationship between mutuality and its organizational forms is emerging as a central area of investigation. Recent ethnographies highlight a tendency towards an informal formalization of mutual help arrangements and the importance of ritual and symbolic aspects in legitimizing novel types of solidarities. This collection of articles aims to contribute to the study of the uneven and partial formalization of institutions of mutuality, with a particular focus on diverse modes of belonging and identity in the new networks of solidarity in Africa.

The topic of contemporary informality within changing regulatory regimes and bureaucracy was examined in the 2012 Africa special issue 'Popular economies in South Africa' (Hull and James 2012). Instead of viewing informality as peripheral to the economy, the collection revealed that economic practices and ideologies are best understood by placing informalization at the centre of the analysis. The cluster of papers in this issue expands these concerns with comparative perspectives on African mutualities, highlighting the importance of affective and normative elements of modern solidarity and cooperation. It uncovers the role of mutual assistance organizations as important channels for new types of resources, values and freedoms, and discusses their broader impacts in the present-day contexts of chronic instability. Reaching beyond the dualities of the formalistsubstantivist debate, the investigation of mutualities reveals the formal and informal as interdependent dimensions of finance that enable economic growth as well as inequalities, upward mobility as well as deprivation.

One of the themes highlighted in most of the papers in this collection is the centrality of the organizational form in contemporary African mutualities. This can be expressed in the growing importance of ritual activities, but also of pronounced group hierarchies, written codes and by-laws.

Rodima-Taylor's study on Tanzanian cooperative work and savings groups discusses the complex and uneven formalization of mutual help associations. The intermingling of diverse organizational elements has contributed to the ability of the groups to integrate novel types of resources and categories of participants within the conditions of a spreading money economy. The contribution by Bähre explores conflicts that emerge when warlords, the state and private business draw on mutuality within South African taxi associations. The changing political landscape has led to new interdependencies which became visible through new forms 
of identification and belonging, but were also reflected in new exclusions as deprivation endured. The central importance of ritual in mutual help activities and its complex relationship with evolving reciprocities are the focus of Ainslie's study. In the rural villages of Eastern Cape Province, people are turning to sophisticated and costly ancestor rituals to re-establish social ties weakened by growing mobility and decreasing agricultural cooperation. Shipton's comparative piece discusses trust, kinship and solidarity in Africa and beyond, calling for a broader, interdisciplinary view. Peebles' article examines the issues of boundary making within financial mutuals from a global policy perspective, exploring the strategies of mutuality that the 'unbanked' employ to counter their forced separation from the global economy. As the articles reveal, the environments of chronic uncertainty in Africa have sometimes impacted adversely on existing patterns of cooperation, but they have also facilitated the rise of new spaces for contesting and legitimizing novel-and often more strongly institutionalizedsolidarities.

\section{REFERENCES}

Bähre, E. (2007) Money and Violence: financial self-help groups in a South African township. Leiden: Brill.

Bryceson, D. (2010) 'Africa at work: transforming occupational identity and morality' in D. Bryceson (ed.), How Africa Works: occupational change, identity and morality. Rugby: Practical Action Publishing.

Comaroff, J. and J. L. Comaroff (eds) (2012) Theory from the South. London: Paradigm Publishers.

Guyer, J. I. (2004) Marginal Gains: monetary transactions in Atlantic Africa. Chicago IL: University of Chicago Press.

Hart, K. and H. Ortiz (2008) 'Anthropology in the financial crisis', Anthropology Today 24 (6): 1-3.

Hart, K., J. Laville and A. Cattani (2010) 'Building the human economy together' in K. Hart, J. Laville and A. Cattani (eds), The Human Economy: a citizen's guide. Cambridge: Polity Press.

Hull, E. and D. James (2012) 'Introduction: popular economies in South Africa', Africa 82 (1): 1-19.

Lindell, I. (2010) 'Introduction: the changing politics of informality: collective organizing, alliances and scales of engagement' in I. Lindell (ed.), Africa's Informal Workers: collective agency, alliances and transnational organizing in urban Africa. London and New York NY: Zed Books.

Maurer, B. (2005) 'The anthropology of money', Annual Review of Anthropology 35: $15-36$.

Meagher, K. (2010) Identity Economics: social networks and the informal economy in Nigeria. London: James Currey.

Rodima-Taylor, D. (2013) 'Gathering up mutual help: the relational freedoms of Tanzanian market-women', Social Analysis 57 (3): 76-94. 